\title{
Diabetes mellitus and risk factors in human immunodeficiency virus-infected individuals at Jimma University Specialized Hospital, Southwest Ethiopia
}

This article was published in the following Dove Press journal: Diabetes, Metabolic Syndrome and Obesity: Targets and Therapy 15 April 2015

Number of times this article has been viewed

\author{
Abdurehman Eshete \\ Mohammed \\ Tilahun Yemane Shenkute \\ Waqtola Cheneke Gebisa \\ Department of Medical Laboratory \\ Sciences and Pathology, College of \\ Health Sciences, Jimma University, \\ Jimma, Ethiopia
}

Correspondence: Abdurehman Eshete Mohammed

Department of Medical Laboratory Sciences and Pathology, College of Health Sciences, Jimma University, PO Box 409, Jimma, Ethiopia

Tel +25I 934580372

Email aeshete8@gmail.com
Background: Globally, diabetes is rising dramatically causing high health burden in low- and middle-income countries. It is estimated that about 382 million people had diabetes in 2013. In 2013, diabetes caused 5.1 million deaths globally. Almost $80 \%$ of diabetes deaths occur in low- and middle-income countries.

Purpose: To assess the magnitude of diabetes mellitus (DM) and associated risk factors in human immunodeficiency virus (HIV)-infected individuals.

Methods: An institution-based cross-sectional study was conducted from April to May 2014 at Jimma University Specialized Hospital. Convenient sampling technique was implemented. Sociodemographic and anthropometric data were collected by senior clinical nurses. Venous blood was collected from each study participant. Serum glucose and lipid profile of the study participants was measured using HumaStar 80 spectrophotometer. Data were analyzed using SPSS version 20. Bivariate and multivariate logistic regressions were utilized.

Results: A total of 393 HIV-infected individuals of age ranging from 21 years to 75 years had enrolled in this study. The overall prevalence of DM in this study was $6.4 \%(n=25)$. Two hundred and ninety-one (74\%) and $77(19.6 \%)$ of the study participants had normal (70-110 mg/dL) and impaired (111-125 mg/dL) fasting blood glucose values, respectively. After adjusting for the other variables, age (adjusted odds ratio $[\mathrm{AOR}]=4.812,95 \%$ confidence interval $[\mathrm{CI}]: 1.668-13.881$, $P=0.004$ ), duration of highly active antiretroviral therapy (HAART) (AOR $=26.928,95 \% \mathrm{CI}$ : 3.722-194.822, $P=0.001$ ), hypertension (AOR $=4.779,95 \% \mathrm{CI}: 1.646-13.874, P=0.004$ ), and low-density lipoprotein cholesterol ( $\mathrm{AOR}=5.669,95 \% \mathrm{CI}$ : $1.849-17.382, P=0.004)$ were significantly associated with DM.

Conclusion: HAART may have an impact on the cause of diabetes. Hence, HIV-infected individuals should be screened for diabetes, both before and after initiation of HAART.

Keywords: diabetes mellitus, human immunodeficiency virus, Jimma, Ethiopia

\section{Introduction}

Diabetes mellitus (DM) is a group of metabolic diseases characterized by chronic hyperglycemia resulting from defects in insulin secretion, insulin action, or both. ${ }^{1}$ It is the most common disorder of carbohydrate metabolism characterized by elevated blood glucose level. ${ }^{2}$

The global burden of diabetes is rising dramatically worldwide. ${ }^{3}$ The International Diabetes Federation estimates that 382 million people had diabetes in 2013; by 2035, this will rise to 592 million worldwide. In 2013, diabetes caused 5.1 million deaths globally; every 
6 seconds, a person die with diabetes. Almost $80 \%$ of diabetes deaths occur in low- and middle-income countries. ${ }^{4}$

$\mathrm{DM}$ is a common disorder affecting individuals of all age groups. Similar to the general population, human immunodeficiency virus (HIV)-infected individuals may also develop DM. ${ }^{5}$ Three subgroups of patients with diabetes and HIV can be identified: patients with preexisting diabetes who contract HIV, those who are diagnosed to have diabetes at the onset of HIV infection, and HIV-infected individuals who develop hyperglycemia after starting highly active antiretroviral therapy (HAART). ${ }^{6}$

Acquired immunodeficiency syndrome (AIDS) is still a disastrous infectious disease posing considerable negative impact on quality of life to individuals and communities. It weakens economic and social performance of the infected individuals, which may result in poor mental and/or physical health. ${ }^{7}$ According to the 2013 United Nations report, globally, an estimated 35.3 million people were living with HIV in 2012, 2.3 million people became newly infected with HIV, and 1.6 million people died from AIDS-related illnesses. ${ }^{8}$

In sub-Saharan Africa, in 2012, a total of 25 million people were living with HIV, 1.6 million people were newly infected with HIV, and 1.2 million were estimated to have died due to AIDS. ${ }^{9}$ Killing the economically active population in particular, HIV/AIDS is destroying the very fabric of societies throughout the continent. ${ }^{10}$

Globally, 12.9 million people living with HIV were receiving HAART in 2013, of whom 11.7 million were receiving antiretroviral therapy (ART) in low- and middle-income countries. ${ }^{11}$ In Ethiopia, about 1.2 million people were estimated to be living with HIV in $2011,{ }^{12}$ among whom $62 \%$ had access to ART. ${ }^{13}$

Introduction of HAART in developing countries with high prevalence of HIV has been recognized as a public health priority. The number of people with access to HAART in sub-Saharan Africa is estimated to have increased tenfold over the last 3 years. ${ }^{4}$ Benefits of HAART include suppression of viral load, improvement in cluster of differentiation 4 count, decrease in opportunistic infections and length of hospital stay, and reduction in mortality. ${ }^{6}$

As treatment of HIV advances and access to therapy improves, the incidence of HIV-associated diabetes is bound to grow. HAART may lead to increase in metabolic dysfunctions, including insulin resistance, diabetes, dyslipidemia, lipodystrophic and cardiovascular diseases, ${ }^{6,14-16}$ hypercholesterolemia, low levels of high-density lipoprotein cholesterol (HDL-C), hypertriglyceridemia, lactic acidemia, and hypercoagulopathy. ${ }^{17-20}$
HIV-infected persons may be at increased risk of developing Type $2 \mathrm{DM}$ as a result of viral coinfection and adverse effects of treatment. ${ }^{21,22}$ Death due to DM in HIV/AIDSinfected individuals is increasing in the era of HAART. ${ }^{23}$

Coexistence of DM in HIV-infected individuals may complicate management of HIV infection, increasing the risk of morbidity and mortality of those individuals. In Ethiopia, there is no adequate information on the magnitude of DM in $\mathrm{HIV}$-infected individuals. Therefore, the aim of this study is to determine the magnitude of DM and associated factors in HIV-infected individuals.

\section{Materials and methods \\ Study area}

The study was conducted at Jimma University Specialized Hospital (JUSH) comprehensive chronic care and training center. The hospital is found in Jimma town, and the town is located $335 \mathrm{~km}$ southwest of Addis Ababa. The hospital serves a total of five million people in Southwest Ethiopia. According to the 2007 Central Statistical Agency census report, the total projected population of Jimma town is 120,960. The town has a characteristic tropical highland climate condition, heavy rainfall, warm temperature, and long wet period. ${ }^{24}$ In April 2014, a total of 7,288 HIV-infected individuals were registered/attending JUSH comprehensive chronic care and training center. Out of these, 4,277 (58.6\%) were on HAART, and the remaining 3,011 (41.4\%) were HAART naïve.

\section{Study design and period}

Institution-based cross-sectional study was conducted at JUSH in April and May 2014.

\section{Sample size determination and sampling technique}

The sample size was calculated by using single-population proportion formula, with the following assumptions: estimate of prevalence $(50 \%)$, margin of error $(0.05)$, 95\% confidence interval (CI), and 10\% for anticipated nonresponse. This gave us a sample size of 403 individuals. Study participants were included in the study using convenient sampling technique.

\section{Data collection procedures}

\section{Sociodemographic and anthropometric data}

Sociodemographic and clinical data were collected using structured questionnaire. Moreover, anthropometric (weight, height, waist, and hip) and blood pressure data were collected. 
These data were collected by two experienced clinical nurses.

\section{Blood specimen collection and laboratory analysis}

Approximately $5 \mathrm{~mL}$ of fasting venous blood specimen was collected from each consenting study participant. Serum was separated from the whole blood at Clinical Chemistry Laboratory of Department of Medical Laboratory Sciences and Pathology, following standard procedures. Serum glucose, total cholesterol, triglyceride, and HDL-C were measured. The glucose and lipid profile tests were analyzed by HumaStar 80 spectrophotometer (Human Diagnostic Company, Wiesbaden, Germany). The reagents used for measurement of the glucose and lipid profile were supplied by Human Gesellschaft für Biochemica und Diagnostica $\mathrm{mbH}$ (Wiesbaden, Germany). The low-density lipoprotein cholesterol (LDL-C) was calculated by using this formula, $\mathrm{LDL}=\mathrm{TC}-\mathrm{HDL}-(\mathrm{TG} / 5)$, where $\mathrm{TC}$ represents total cholesterol and TG represents triglyceride. ${ }^{25}$

The study participants were classified as diabetic using World Health Organization (WHO) diagnostic criteria when fasting plasma glucose was $\geq 126 \mathrm{mg} / \mathrm{dL}$. ${ }^{26}$

\section{Anthropometric parameters}

The height and body weight were measured to a precision of $0.1 \mathrm{~cm}$ and $0.1 \mathrm{~kg}$, respectively, using a digital balance with height measurement attached to it. Body mass index (BMI) was calculated as weight in kilograms divided by the square of the height in meters. Based on the BMI, the study participants were classified as underweight, normal, overweight, and obese when the BMI is $<18.5 \mathrm{~kg} / \mathrm{m}^{2}, 18.5-24.99 \mathrm{~kg} / \mathrm{m}^{2}$, $25-29.99 \mathrm{~kg} / \mathrm{m}^{2}$, and $\geq 30 \mathrm{~kg} / \mathrm{m}^{2}$, respectively. ${ }^{27}$

\section{Blood pressure}

Three blood pressure measurements were taken after taking at least 5 minutes of rest in between the measurements. Average of the second and third readings was finally recorded. A study participant was classified to have normal blood pressure if both systolic blood pressure (SBP) and diastolic blood pressure (DBP) were normal; meanwhile, a participant was classified as having mild, moderate, and severe hypertension when SBP or DBP was mildly raised, moderately raised, and severely raised, respectively. ${ }^{28}$

\section{Data analysis}

To assure the quality of the data, standard operating procedures were followed during specimen collection and all other laboratory procedures. Training was given to the data collectors before the actual work started. The reagents and instruments were checked for proper functioning before the start of the actual work. Both normal and pathological quality controls were run for detecting errors and to validate patient result. The anthropometric and blood pressure measurements were done strictly by skilled senior clinical nurse. The questionnaires were checked for completeness and consistency.

Data from the laboratory investigation, structured questionnaires, and other measurements were coded and entered to Epi Info version 7.1.4.0 (Centers for Disease Control and Prevention $[\mathrm{CDC}]$ ) and then exported to SPSS version 20 for analysis. Descriptive statistics and inferential statistical tests, chi-square test, bivariate and multivariate logistic regression tests were utilized. For variables that do not satisfy the assumptions of chi-square test, the Fisher's exact test was used instead of Pearson's chi-square test. The variables with $P$-value less than 0.25 in bivariate logistic regression analysis were nominated for multivariate logistic regression analysis.

Before running the multiple binary logistic regressions, Hosmer and Lemeshow goodness of fit test was done. In multivariate logistic regression test, $P$-values less than 0.05 were taken as cut-off value for significant association.

\section{Ethical considerations}

Ethical clearance was obtained from Jimma University ethical review committee, official support letter to conduct the study was obtained from JUSH administrators, and written informed consent was taken from each study subject after clear orientation of the study objective. All the results were kept confidential, and the privacy of the study participants was protected. Positive findings were reported to the clinician working at JUSH comprehensive chronic care and training center for better management.

\section{Results \\ Sociodemographic characteristics of the study participants}

A total of 403 study participants were enrolled in this study. Ten of the blood samples were not appropriate for the assays, and hence were excluded from analysis. Accordingly, complete data of 393 HIV-infected individuals were collected. Age of the study participants ranged from 21 years to 75 years (mean age $37.9 \pm 11.18$ standard deviation). Two hundred and eighty-four (72.3\%) of the study participants were HAART experienced, and the rest 109 (27.7\%) were HAART naïve. The majority $(71.2 \%)$ of the study participants were less than 40 years of age. Most of the study participants $(66.9 \%)$ were 
females, and $348(88.5 \%)$ of the study participants were from urban areas. One hundred and eighty-six (47.3\%) of the study participants were employed. Most of the study participants were literate (78.4\%) and married (62.3\%). About half of the study participants (51.4\%) were orthodox, and 153 (38.9\%) of the study participants were Oromo (Table 1).

\section{Magnitude of DM in the study participants}

The overall prevalence of DM in this study was $6.4 \%(n=25)$. Seven of the DM-positive individuals knew about their DM status before our study, and they did not start using drug. Two hundred and ninety-one (74\%) and $77(19.6 \%)$ of the study participants had normal glucose value (70-110 mg/dL) and impaired fasting glucose value (111-125 mg/dL), respectively (Figure 1).

\section{Risk factors associated with DM}

In this study, several sociodemographic and other associated factors to DM were assessed. With regard to the association of DM with age, $15(13.3 \%)$ and ten $(3.6 \%)$ of the

Table I Sociodemographic factors versus DM in HIV-infected individuals $(n=393)$ at JUSH, Southwest Ethiopia, 2014

\begin{tabular}{|c|c|c|c|c|}
\hline \multirow[t]{2}{*}{ Variables } & \multicolumn{2}{|c|}{$\begin{array}{l}\text { Glucose result: } \\
\text { number }(\%)\end{array}$} & \multirow{2}{*}{$\begin{array}{l}\text { Total, } \\
\text { number } \\
(\%)\end{array}$} & \multirow{2}{*}{$\begin{array}{l}P \text {-value } \\
\text { of } \chi^{2} \\
\text { test }\end{array}$} \\
\hline & Normal & DM & & \\
\hline \multicolumn{5}{|l|}{ Age (years) } \\
\hline$<40$ & $270(96.4)$ & $10(3.6)$ & $280(7 I .2)$ & 0.001 \\
\hline$\geq 40$ & 98 (86.7) & $15(13.3)$ & $113(28.8)$ & \\
\hline \multicolumn{5}{|l|}{ Sex } \\
\hline Male & $122(93.8)$ & $8(6.2)$ & $130(33.1)$ & 0.906 \\
\hline Female & $246(93.5)$ & $17(6.5)$ & $263(66.9)$ & \\
\hline \multicolumn{5}{|l|}{ Occupation } \\
\hline Farmer & $37(100)$ & 0 & $37(9.4)$ & \\
\hline Merchant & 78 (88.6) & $10(11.4)$ & $88(22.4)$ & \\
\hline Employed & $175(94.1)$ & II (5.9) & $186(47.3)$ & \\
\hline Unemployed & $78(95.1)$ & $4(4.9)$ & $82(20.9)$ & \\
\hline \multicolumn{5}{|l|}{ Residence } \\
\hline Urban & $326(93.7)$ & $22(6.3)$ & $348(88.5)$ & \\
\hline Rural & $42(93.3)$ & $3(6.7)$ & 45 (II.5) & \\
\hline \multicolumn{5}{|l|}{ Educational status } \\
\hline Literate & $287(93.2)$ & $21(6.8)$ & $308(78.4)$ & 0.480 \\
\hline Illiterate & 81 (95.3) & $4(4.7)$ & $85(21.6)$ & \\
\hline \multicolumn{5}{|l|}{ Marital status } \\
\hline Married & $233(95.1)$ & $12(4.9)$ & $245(62.3)$ & \\
\hline Single & $50(94.3)$ & $3(5.7)$ & $53(13.5)$ & \\
\hline Widowed & $44(89.8)$ & $5(10.2)$ & $49(12.5)$ & \\
\hline Divorced & $41(89.1)$ & $5(10.9)$ & 46 (II.7) & \\
\hline \multicolumn{5}{|l|}{ Drug status } \\
\hline HAART experienced & $260(91.5)$ & $24(8.5)$ & $284(72.3)$ & 0.006 \\
\hline HAART naïve & $108(99.1)$ & I (0.9) & $109(27.7)$ & \\
\hline
\end{tabular}

Abbreviations: DM, diabetes mellitus; HIV, human immunodeficiency virus; JUSH, Jimma University Specialized Hospital; HAART, highly active antiretroviral therapy. study participants who were DM positive were $\geq 40$ years and $<40$ years, respectively. There was a strong statistically significant association between DM and age $(P=0.001)$. In addition to this, eleven (5.9\%) and ten (11.4\%) of the employed and merchandizing study participants were positive for DM, respectively (Table 1 ).

On the other side, 17 (6.5\%), $21(6.8 \%), 12(4.9 \%), 22$ (6.3\%), and $24(8.5 \%)$ of the females, literates, married, urban residents, and HAART experienced of the study participants were DM positive, respectively. There was no significant association of DM with sex $(P=0.906)$ and educational status ( $P=0.480)$, but drug status had statistically significant association with DM $(P=0.006)$ (Table 1).

Thirty-three (8.4\%) of the study participants had the three symptoms of DM (polydipsia, polyuria, and polyphagia), and $58(14.8 \%)$ of the study participants had one or two of the symptoms. Among the study participants who have the three signs and symptoms, 25 (75.8\%) of them were positive for DM (Table 2).

The majority (88.3\%) of the study participants had no family history of DM. Of these, 19 (5.5\%) of them had DM. In relation to habit of smoking with DM, $326(83 \%)$ of the study participants reported no habit of smoking. Among these who reported no history of smoking, 22 (6.7\%) were DM positive. There was no statistically significant association with DM in both family history of $\mathrm{DM}(P=0.098)$ and smoking $(P=0.783)$ (Table 2).

With regard to the types of HAART, 126 (32.1\%) of the study participants used the drug combination zidovudine (AZT) + Lamivudine (3TC) + Nevirapine (NVP). Of these, $13(10.3 \%)$ had DM. Additionally, six (7.1\%) of the study participants who were using the drug Tenofovir (TDF) + $3 \mathrm{TC}+$ Efavirenz (EFV) were positive for DM (Table 2).

Almost greater than half (67.4\%) and $44(11.2 \%)$ of the study participants had a normal $\left(18.5-25 \mathrm{~kg} / \mathrm{m}^{2}\right)$ and overweight $\left(25-29.9 \mathrm{~kg} / \mathrm{m}^{2}\right)$ BMI values, respectively. Thirteen $(4.9 \%)$ and ten $(22.7 \%)$ of the study participants who had normal and overweight BMI values were positive for DM, respectively (Table 2).

The majority of the study participants $(85.8 \%)$ were in WHO clinical stage 1 of HIV/AIDS classification. Of these, 24 (7.1\%) of them had DM. On the other hand, 189 (66.5\%) of the study participants were using HAART for greater than or equal to 5 years. Of these, $22(11.6 \%)$ of them had DM. In addition to this, two (2.1\%) of the DM-positive study participants had HAART duration of less than 5 years. There was a statistically significant association between DM and duration of HAART $(P=0.006)$ (Table 2$)$. 


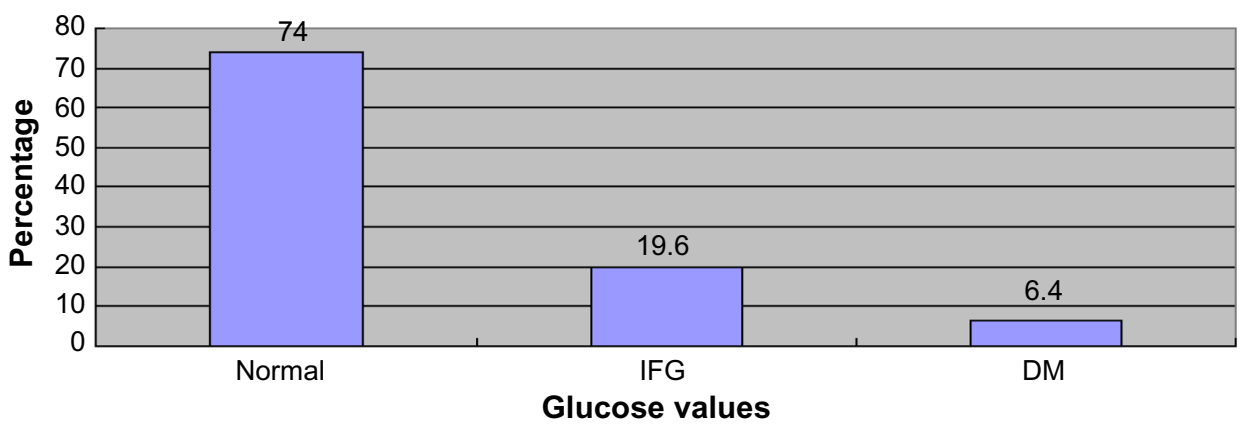

Figure I Classification of serum glucose test values of HIV-infected individuals at JUSH comprehensive chronic care and training center, Southwest Ethiopia, 20 I4. Abbreviations: HIV, human immunodeficiency virus; JUSH, Jimma University Specialized Hospital; IFG, impaired fasting glucose; DM, diabetes mellitus.

Regarding HIV duration, almost half $(51.9 \%)$ of the study participants live with HIV for greater than or equal to 5 years. Of these, 19 (9.3\%) of them had DM. There was a statistically significant association between DM and HIV duration $(P=0.013)$ (Table 2).

In relation to hypertension, 135 (34.4\%) of the study participants had hypertension. Nineteen (14.1\%) of the study participants who had hypertension were DM positive. Six $(2.3 \%)$ of the study participants with DM had normal systolic and diastolic values. There was a statistically significant association between hypertension $(P=0.001)$ and DM (Table 2).

In the bivariate binary logistic regression analysis, variables such as: age (crude odds ratio $[\mathrm{COR}]=4.13,95 \%$ CI: $1.79-9.51, P=0.001)$, drug status $(\mathrm{COR}=9.97,95 \% \mathrm{CI}$ : $1.33-74.62, P=0.025)$, HIV duration ( $\mathrm{COR}=3.13,95 \% \mathrm{CI}$ : $1.22-8.02, P=0.017)$, duration of HAART (COR $=6.13,95 \%$ CI: $1.41-26.6, P=0.016$ ), hypertension ( $\mathrm{COR}=6.88,95 \%$ CI: $2.68-17.68, P=0.001)$, total cholesterol $(\mathrm{COR}=3.67$, 95\% CI: $1.58-8.56, P=0.003)$, and LDL-C (COR $=6.75$, $95 \%$ CI: $2.48-18.38, P=0.001$ ) had statistically significantly association with DM. Additionally, those variables which had a $P$-value less than 0.25 were candidate for multivariate logistic regression analysis (Table 3 ).

After adjusting for the other variables, age (adjusted odds ratio $[\mathrm{AOR}]=4.812,95 \% \mathrm{CI}: 1.668-13.881, P=0.004$ ), duration of HAART (AOR $=26.928,95 \%$ CI: 3.722-194.822, $P=0.001$ ), hypertension (AOR $=4.779,95 \% \mathrm{CI}: 1.646-$ 13.874, $P=0.004)$, and LDL-C (AOR $=5.669,95 \% \mathrm{CI}$ : $1.849-17.382, P=0.004)$ had strong statistically significant association with DM (Table 4).

\section{Discussion}

Ethiopia is one of the countries of the International Diabetes Federation Africa region. The national prevalence of DM was estimated to be $2 \%-3 \%$ in the general population..$^{29}$ In addition to this, the total prevalence of DM in Ethiopian adult population (20-79 years) was $4.36 \%,{ }^{30}$ which is lower than this study (6.4\%). People with diabetes have an increased risk of developing a number of serious health problems. High blood glucose levels can lead to serious diseases affecting the heart, blood vessels, eyes, kidneys, and nerves. On the other side, HIV/AIDS is not curable, and it is a disastrous disease that compromises the immune system of the patient. So, the combination of the two diseases will increase the burden of morbidity and mortality of the HIV-infected individuals. HAART might have an impact on the cause of diabetes. This could be the probable reason why the present study is having higher prevalence of DM than the general and the adult population of Ethiopia.

The prevalence of this study was lower than reports from Senegal (14.5\%), ${ }^{31}$ Tanzania (24.7\%), ${ }^{32}$ Thai (27\%), ${ }^{33}$ Israel $(22.9 \%),{ }^{34}$ California, USA (12\%), ${ }^{35}$ and Romania (13\%). ${ }^{36}$ On the other hand, the prevalence of DM in this study was comparable to the study conducted in Wolayta Sodo, Ethiopia (8\%), ${ }^{14}$ and the prevalence of DM in this study was higher than the study conducted in Zambia (2.7\%). ${ }^{37}$ In this study, higher prevalence of impaired fasting glucose was seen, which is inconsistent with a study done in Romania $(4.34 \%)^{36}$ and Zambia (1.3\%). ${ }^{37}$ The observed difference in the prevalence of DM could be due to variation in lifestyle, HAART regimens, and age distribution of the HIV-infected individuals.

In this study, most of the DM-positive individuals were greater than or equal to 40 years of age. When age is increased, the prevalence of DM also increases, which was consistent with the studies done in New York, USA, ${ }^{21}$ Wolayta Sodo, Ethiopia, ${ }^{14}$ Texas, USA, ${ }^{38}$ USA, ${ }^{39}$ and Zambia. ${ }^{37}$

The majority of the study participants and most of the DM-positive individuals in this study were females (66.9\%), which was consistent with the studies done in Tanzania, Muhabi national hospital (56\%), ${ }^{32}$ Wolayta Sodo, Ethiopia 
Table 2 Clinical factors versus DM in HIV-infected individuals $(n=393)$ at JUSH, Southwest Ethiopia, 2014

\begin{tabular}{|c|c|c|c|c|}
\hline \multirow[t]{2}{*}{ Variables } & \multicolumn{2}{|c|}{ Glucose result: number (\%) } & \multirow{2}{*}{$\begin{array}{l}\text { Total, } \\
\text { number (\%) }\end{array}$} & \multirow{2}{*}{$\begin{array}{l}P \text {-value } \\
\text { of } \chi^{2} \text { test }\end{array}$} \\
\hline & Normal & DM & & \\
\hline \multicolumn{5}{|l|}{ Symptoms } \\
\hline No symptoms & $302(100)$ & 0 & $302(76.8)$ & \\
\hline All symptoms & $8(24.2)$ & $25(75.8)$ & $33(8.4)$ & \\
\hline Polydipsia or polyuria or polyphagia & $58(100)$ & 0 & $58(14.8)$ & \\
\hline \multicolumn{5}{|l|}{ Family history of DM } \\
\hline Yes & $40(87)$ & $6(13)$ & $46(11.7)$ & $0.098 *$ \\
\hline No & $328(94.5)$ & $19(5.5)$ & $347(88.3)$ & \\
\hline \multicolumn{5}{|l|}{ Smoking } \\
\hline Never smoked & $304(93.3)$ & $22(6.7)$ & $326(83)$ & $0.783^{*}$ \\
\hline Former smoker & $64(95.5)$ & $3(4.5)$ & $67(17)$ & \\
\hline \multicolumn{5}{|l|}{ Types of HAART } \\
\hline AZT/3TC/EFV & $27(93.1)$ & $2(6.9)$ & $29(7.4)$ & \\
\hline TDF/3TC/NVP & $38(92.7)$ & $3(7.3)$ & $4 \mathrm{I}(10.4)$ & \\
\hline $\mathrm{AZT} / 3 \mathrm{TC} / \mathrm{NVP}$ & I I 3 (89.7) & $13(10.3)$ & $126(32.1)$ & \\
\hline TDF/3TC/EFV & $78(92.9)$ & $6(7.1)$ & $84(21.4)$ & \\
\hline $\begin{array}{l}\mathrm{ABC} / \mathrm{DDI} / \mathrm{LPV} / \mathrm{r} / \mathrm{TDF}+\mathrm{DDI}+ \\
\mathrm{LPV} / \mathrm{r} / \mathrm{DDI}+3 \mathrm{TC}+\mathrm{LPV} / \mathrm{r}\end{array}$ & $4(100)$ & 0 & $4(\mathrm{I})$ & \\
\hline HAART naïve & $108(99.1)$ & $\mathrm{I}(0.9)$ & $109(27.7)$ & \\
\hline \multicolumn{5}{|l|}{ WHO clinical stage of HIV/AIDS } \\
\hline Stage I & $313(92.9)$ & $24(7.1)$ & $337(85.8)$ & \\
\hline Stage 2 & $32(100)$ & 0 & $32(8.1)$ & \\
\hline Stage 3 & $21(100)$ & 0 & $21(5.3)$ & \\
\hline Stage 4 & $2(66.7)$ & I (33.3) & $3(0.8)$ & \\
\hline \multicolumn{5}{|l|}{ HIV duration (years) } \\
\hline$<5$ & $183(96.8)$ & $6(3.2)$ & $189(48.1)$ & 0.013 \\
\hline$\geq 5$ & $185(90.7)$ & $19(9.3)$ & $204(51.9)$ & \\
\hline \multicolumn{5}{|l|}{ Duration of HAART (years) } \\
\hline$<5$ & $93(97.90)$ & $2(2.1)$ & $95(33.5)$ & 0.006 \\
\hline$\geq 5$ & $167(88.4)$ & $22(11.6)$ & $189(66.5)$ & \\
\hline \multicolumn{5}{|l|}{ Hypertension } \\
\hline Yes & 116 (85.9) & $19(14.1)$ & $135(34.4)$ & 0.001 \\
\hline No & $252(97.70)$ & $6(2.3)$ & $258(65.6)$ & \\
\hline \multicolumn{5}{|l|}{ BMI $\left(\mathrm{kg} / \mathrm{m}^{2}\right)$} \\
\hline$<18.5$ & 77 (98.7) & $\mathrm{I}(\mathrm{I} .3)$ & $78(19.8)$ & \\
\hline $18.5-25$ & $252(95.1)$ & $13(4.9)$ & $265(67.4)$ & \\
\hline $25.1-29.9$ & $34(77.3)$ & $10(22.7)$ & $44(\mathrm{II} .2)$ & \\
\hline$\geq 30$ & $5(83.3)$ & I (I6.7) & $6(1.5)$ & \\
\hline \multicolumn{5}{|l|}{ Total cholesterol (mg/dL) } \\
\hline$<200$ & $248(96.5)$ & $9(3.5)$ & $257(65.4)$ & 0.001 \\
\hline$\geq 200$ & $120(88.2)$ & $16(11.8)$ & $136(34.6)$ & \\
\hline \multicolumn{5}{|l|}{ Triglycerides (mg/dL) } \\
\hline$<150$ & $128(96.2)$ & $5(3.8)$ & $133(33.8)$ & 0.131 \\
\hline$\geq 150$ & $240(92.3)$ & $20(7.7)$ & $260(66.2)$ & \\
\hline \multicolumn{5}{|l|}{ LDL-C (mg/dL) } \\
\hline$<130$ & $231(97.9)$ & $5(2.1)$ & $236(60.1)$ & 0.001 \\
\hline$\geq 130$ & I 37 (87.3) & $20(12.7)$ & 157 (39.9) & \\
\hline \multicolumn{5}{|l|}{ HDL-C (mg/dL) } \\
\hline$<40$ & $328(92.9)$ & $25(7.1)$ & $353(89.8)$ & $0.093 *$ \\
\hline$\geq 40$ & $40(100)$ & 0 & $40(10.2)$ & \\
\hline
\end{tabular}

Notes: Statistically significant at $P<0.05$. *P-value of Fisher's exact test.

Abbreviations: DM, diabetes mellitus; HIV, human immunodeficiency virus; JUSH, Jimma University Specialized Hospital; HAART, highly active antiretroviral therapy; WHO, World Health Organization; AIDS, acquired immunodeficiency syndrome; BMI, body mass index; LDL-C, low-density lipoprotein cholesterol; HDL-C, high-density lipoprotein cholesterol; AZT, zidovudine; 3TC, Lamivudine; EFV, Efavirenz; TDF, Tenofovir; NVP, Nevirapine; ABC, Abacavir; DDI, Didanosine; LPV/r, Lopinavir/ritonavir. 
Table 3 Binary logistic regression analysis of variables considered to be associated with DM in HIV-infected individuals ( $n=393$ ) at JUSH Southwest Ethiopia, 2014

\begin{tabular}{|c|c|c|c|c|c|}
\hline \multirow[t]{2}{*}{ Variables } & \multicolumn{2}{|c|}{ Glucose result: number (\%) } & \multirow[t]{2}{*}{ COR } & \multirow[t]{2}{*}{$95 \% \mathrm{Cl}$} & \multirow[t]{2}{*}{$P$-value } \\
\hline & Normal & DM & & & \\
\hline \multicolumn{6}{|l|}{ Age (years) } \\
\hline$<40$ & $270(96.4)$ & $10(3.6)$ & I & & 0.001 \\
\hline$\geq 40$ & $98(86.7)$ & $15(13.3)$ & 4.13 & I.797-9.505 & \\
\hline \multicolumn{6}{|l|}{ Sex } \\
\hline Male & $122(93.8)$ & $8(6.2)$ & I & & 0.906 \\
\hline Female & $246(93.5)$ & $17(6.5)$ & 1.05 & $0.442-2.510$ & \\
\hline \multicolumn{6}{|l|}{ Education status } \\
\hline Literate & $287(93.2)$ & $21(6.8)$ & 1.48 & $0.495-4.439$ & 0.482 \\
\hline Illiterate & $81(95.3)$ & $4(4.7)$ & I & & \\
\hline \multicolumn{6}{|l|}{ Marital status } \\
\hline Married & $233(95.1)$ & $12(4.9)$ & I & & 0.131 \\
\hline Single/widowed/divorced & 135 (9|.2) & $13(8.8)$ & 1.87 & $0.829-4.215$ & \\
\hline \multicolumn{6}{|l|}{ Drug status } \\
\hline HAART experienced & $260(9 \mid .5)$ & $24(8.5)$ & 9.97 & $|.332-74.62|$ & 0.025 \\
\hline HAART naïve & $108(99.1)$ & I $(0.9)$ & I & & \\
\hline \multicolumn{6}{|l|}{ HIV duration (years) } \\
\hline$<5$ & $183(96.8)$ & $6(3.2)$ & I & & 0.017 \\
\hline$\geq 5$ & $185(90.7)$ & $19(9.3)$ & 3.13 & $1.223-8.021$ & \\
\hline \multicolumn{6}{|l|}{ Duration of HAART (years) } \\
\hline$\leq 5$ & $93(97.9)$ & $2(2.1)$ & I & & 0.016 \\
\hline$>5$ & $167(88.4)$ & $22(11.6)$ & 6.13 & $|.409-26.63|$ & \\
\hline \multicolumn{6}{|l|}{ Hypertension } \\
\hline Yes & 116 (85.9) & $19(14.1)$ & 6.88 & $2.677-17.678$ & 0.001 \\
\hline No & $252(97.7)$ & $6(2.3)$ & I & & \\
\hline \multicolumn{6}{|l|}{ Total cholesterol (mg/dL) } \\
\hline$<200$ & $248(96.5)$ & $9(3.5)$ & I & & 0.003 \\
\hline$\geq 200$ & $120(88.2)$ & $16(11.8)$ & 3.67 & $1.578-8.555$ & \\
\hline \multicolumn{6}{|l|}{ Triglycerides (mg/dL) } \\
\hline$<150$ & $128(96.2)$ & $5(3.8)$ & I & & 0.139 \\
\hline$\geq 150$ & $240(92.3)$ & $20(7.7)$ & 2.13 & $0.782-5.818$ & \\
\hline \multicolumn{6}{|l|}{ LDL-C (mg/dL) } \\
\hline$<130$ & $231(97.9)$ & $5(2.1)$ & I & & 0.001 \\
\hline$\geq 130$ & I 37 (87.3) & $20(12.7)$ & 6.75 & $2.475-18.380$ & \\
\hline
\end{tabular}

Note: Statistically significant at $P<0.05$.

Abbreviations: DM, diabetes mellitus; HIV, human immunodeficiency virus; JUSH, Jimma University Specialized Hospital; COR, crude odds ratio; Cl, confidence interval; HAART, highly active antiretroviral therapy; LDL-C, low-density lipoprotein cholesterol.

$(51 \%),{ }^{14}$ and southern India $(54 \%)^{40}$ and inconsistent with the studies done in Malaysia $(18.9 \%)^{7}$ and People's Republic of China $(24.3 \%){ }^{41}$

In this study, $11.7 \%$ of the study participants had a family history of DM, which is inconsistent with the study done in Texas, USA $(60 \%) .{ }^{38}$ The majority of the study participants $(83 \%)$ in this study had no habit of smoking in their life, and there was no association between DM and smoking, which was consistent with the study done in Malaysia. ${ }^{7}$

In this study, most of the study participants (99\%) were using the combination of nucleoside reverse transcriptase inhibitors and non-nucleoside reverse transcriptase inhibitors, which was consistent with the studies done in Malaysia
$(90.7 \%)^{7}$ and inconsistent with the study done in Texas, USA $(77.9 \%),{ }^{38}$ in which most of the study participants were using protease inhibitors. The observed difference could be due to variation in types and availability of HAART regimens.

Out of 189 study participants who had long duration of HAART ( $\geq 5$ years), $11.6 \%$ were DM positive, versus $2 \%$ DM positive in another group, that is, those who had short duration of HAART ( $<5$ years), which is consistent with the studies done in Wolayta Sodo, Ethiopia $(12.68 \%)^{14}$ and Senegal (32.8\%). ${ }^{40}$ The above-observed difference could be due to variation in the types of HAART regimens.

In this study, $34 \%$ of the study participants showed hypertension, which was comparable to the study done in 
Table 4 Multivariate logistic regression analysis of variables associated with DM in HIV-infected individuals ( $n=393)$ at JUSH comprehensive chronic care and training center, Southwest Ethiopia, 2014

\begin{tabular}{|c|c|c|c|c|c|}
\hline \multirow[t]{2}{*}{ Variables } & \multicolumn{2}{|c|}{ Glucose result, number (\%) } & \multirow[t]{2}{*}{ AOR } & \multirow[t]{2}{*}{$95 \% \mathrm{Cl}$} & \multirow[t]{2}{*}{$P$-value } \\
\hline & Normal & DM & & & \\
\hline \multicolumn{6}{|l|}{ Age (years) } \\
\hline$<40$ & $270(96.4)$ & $10(3.6)$ & I & & \\
\hline$\geq 40$ & $98(86.7)$ & $15(13.3)$ & 4.812 & $1.668-13.88 \mid$ & 0.004 \\
\hline \multicolumn{6}{|c|}{ Duration of HAART (years) } \\
\hline$<5$ & $93(97.9)$ & $2(2.1)$ & 1 & & \\
\hline$\geq 5$ & $167(88.4)$ & $22(11.6)$ & 26.928 & $3.722-194.822$ & 0.001 \\
\hline \multicolumn{6}{|c|}{ Hypertension } \\
\hline Yes & $116(85.9)$ & $19(14.1)$ & 4.779 & $1.646-13.874$ & 0.004 \\
\hline No & $252(97.7)$ & $6(2.3)$ & I & & \\
\hline \multicolumn{6}{|c|}{ LDL-C (mg/dL) } \\
\hline$<130$ & $231(97.9)$ & $5(2.1)$ & I & & \\
\hline$\geq 130$ & I 37 (87.3) & $20(12.7)$ & 5.669 & I.849-17.382 & 0.004 \\
\hline
\end{tabular}

Note: Statistically significant at $P<0.05$.

Abbreviations: DM, diabetes mellitus; HIV, human immunodeficiency virus; JUSH, Jimma University Specialized Hospital; AOR, adjusted odds ratio; Cl, confidence interval; HAART, highly active antiretroviral therapy; LDL-C, low-density lipoprotein cholesterol.

Senegal (28.1\%) ${ }^{31}$ higher than a study conducted in Ethiopia $(15.9 \%)^{14}$ and Malaysia $(19.7 \%),{ }^{7}$ and lower than a study conducted in Tanzania (48\%). ${ }^{32}$ The observed difference could be due to variation in types of HAART, duration of HIV infection itself, stage of HIV infection, sex, lifestyle, and age difference of the study participants.

Most of the DM-positive study participants in this study had higher total cholesterol, triglyceride, and LDL-C, and low level of HDL-C, which was consistent with the studies done in Malaysia, ${ }^{7}$ Nigeria, ${ }^{20}$ and Australia. ${ }^{16}$ The above similarity may be due to the similar risk factors of DM.

Most of the DM-positive study participants in this study were from urban areas, and they were merchants and employed because the study is conducted in urban area. Despite this, all of the DM-positive study participants had the three symptoms (polyphagia, polyuria, and polydipsia) of DM. Finally, almost all of the study participants were in WHO clinical stage I of HIV/AIDS and had normal BMI values. This could be because most of the study participants in this study were HAART users and they might take care of themselves.

\section{Conclusion}

We conclude that the magnitude of DM among adult HIVinfected individuals at JUSH comprehensive chronic care and training center was higher than the national estimated prevalence of DM in Ethiopia. Age, duration of HAART, hypertension, and LDL-C had a strong significant association with DM.

It is necessary to routinely screen HIV-infected individuals who are using HAART for DM. All newly diagnosed
HIV-infected individuals should be screened for DM, both before and after initiating HAART. All the adult HIV-infected individuals should be routinely checked for hypertension, and lipid profile tests should be routinely done for screening of lipids abnormality. Moreover, based on our results, hypertension was the potential risk factor for the development of DM in HIV-infected individuals. So, the health professionals who are working in the comprehensive chronic care and training center should create awareness to their HIV-infected individuals about the prevention, diagnosis, and treatment of hypertension and DM to prevent further complication.

Further research is needed to discover the impact of HAART usage and its duration on the development of DM in HIV-infected individuals with large sample size and with longitudinal study.

\section{Acknowledgments}

We thank Jimma University for funding this research. We are thankful to the staffs of JUSH comprehensive chronic care and training center for their support during data collection. We are grateful to the study participants of this study. We are thankful to Mr Melkam Tesfaye for his support in the clinical specimen analysis.

\section{Author contributions}

All authors contributed toward data analysis, drafting and revising the paper and agree to be accountable for all aspects of the work.

\section{Disclosure}

The authors declare that there is no competing interest. 


\section{References}

1. American Diabetes Association. Diagnosis and classification of diabetes mellitus. Diabetes Care. 2013;36(Suppl 1):S67-S74.

2. McPherson RA, Pincus MR. Henry's Clinical Diagnosis and Management by Laboratory Methods. 22nd ed. Philadelphia: Saunders Elsevier; 2011.

3. Hanson MA, Gluckman PD, Ma RC, Matzen P, Biesma RG. Early life opportunities for prevention of diabetes in low and middle income countries. BMC Public Health. 2012;12:1025.

4. International Diabetes Federation Diabetes Atlas. 6th ed; 2013. Available from: http://www.idf.org/diabetesatlas/update-2014. Accessed June 17, 2014.

5. Wiwanitkit V. Primary care for diabetes in HIV-infected patients. Online $J$ Health Allied Sci. 2007;2:1.

6. Kalra S, Kalra B, Agrawal N, Unnikrishnan AG. Understanding diabetes in patients with HIV/AIDS. Diabetol Metab Syndr. 2011;3:2.

7. Hejazi N, Rajikan R, Choong CLK, Sahar S. Metabolic abnormalities in adult HIV infected population on antiretroviral medication in Malaysia: a cross-sectional survey. BMC Public Health. 2013;13:758.

8. Global Report. UNAIDS Report on the Global AIDS Epidemic; 2013. Aavailable from: http://www.unaids.org/en/resources/campaigns/globalreport2013. Accessed June 17, 2014.

9. WHO. Regional HIV and AIDS Statistics and Features; 2012. Available from: http://www.unaids.org/sites/default/files/en/media/unaids/ contentassets/documents/epidemiology/2013/gr2013/201309 epi core en.pdf

10. Vugt MV, Hamers R, Schellekens O, Wit TRD, Reiss P. Diabetes and HIV/AIDS in sub-Saharan Africa: the need for sustainable healthcare systems. Diabetes Care. 2007;52:23-26.

11. WHO. HIV/AIDS Fact Sheet; 2014. Available from: http://www.who. int/mediacentre/factsheets/fs360/en/. Accessed August 13, 2014.

12. Tadewos A, Addis Z, Ambachew H, Banerjee S. Prevalence of dyslipidemia among HIV-infected patients using first-line highly active antiretroviral therapy in Southern Ethiopia: a cross-sectional comparative group study. AIDS Res Ther. 2012;9:31.

13. Konings E, Ambaw Y, Dilley K, Gichangi P, Arega T, Crandall B. Implications of adopting new WHO guidelines for antiretroviral therapy initiation in Ethiopia. Bull World Health Organ. 2012;90:659-663.

14. Sachithananthan V, Loha E, Gose M. Prevalence of diabetes mellitus, hypertension and lipodystrophy in HAART receiving HIV patients in Southern Ethiopia. Int STD Res Rev. 2013;1:1-11.

15. Florescu D, Kotler DP. Insulin resistance, glucose intolerance and diabetes mellitus in HIV-infected patients. Antivir Ther. 2007;12:149-162.

16. Samaras K, Wand H, Law M, Emery S, Cooper D, Carr A. Prevalence of metabolic syndrome in HIV infected patients receiving highly active antiretroviral therapy using international diabetes foundation and adult treatment panel III criteria. Diabetes Care. 2007;30:113-119.

17. Lo YC, Chen MY, Sheng WH, et al. Risk factors for incident diabetes mellitus among HIV-infected patients receiving combination antiretroviral therapy in Taiwan: a case-control study. HIV Med. 2009;10: 302-309.

18. Arama V, Tiliscan C, Streinu-Cercel A, et al; SLD-ART Study Group. Insulin resistance and adipokines serum levels in a Caucasian cohort of HIV-positive patients undergoing antiretroviral therapy: a cross sectional study. BMC Endocr Disord. 2013;13:4.

19. Estrada V, Geijo P, Fuentes-Ferrer M, et al. Dyslipidaemia in HIVinfected women on antiretroviral therapy. Analysis of 922 patients from the Spanish VACH cohort. BMC Womens Health. 2011;11:36.

20. Adewole OO, Eze S, Betiku Y, et al. Lipid profile in HIV/AIDS patients in Nigeria. Afr Health Sci. 2010;10:144-149.

21. Howard AA, Floris-Moore M, Arnsten JH, et al. Disorders of glucose metabolism among HIV-infected women. Clin Infect Dis. 2005;40: 1492-1499.
22. Young F, Critchley JA, Johnstone LK, Unwin NC. A review of comorbidity between infectious and chronic disease in Sub Saharan Africa: TB and diabetes mellitus, HIV and metabolic syndrome, and the impact of globalization. Global Health. 2009;14(5):9.

23. Pacheco AG, Tuboi SH, Faulhaber JC, Harrison LH, Schechter M. Increase in non-AIDS related conditions as causes of death among HIV-infected individuals in the HAART era in Brazil. PLoS One. 2008;3:e1531.

24. UNFPA. Federal Democratic Republic of Ethiopian Population Census Commission, Summary and Statistical Report of 2007 Population and Housing Census. UNFPA Addis Ababa; 2008.

25. Friedewald WT, Levy RI, Frederickson DS. Estimation of the concentration of low density lipoprotein cholesterol in plasma without use of preparative ultracentrifugation. Clin Chem. 1972;18:499-502.

26. WHO. Definition and Diagnosis of Diabetes Mellitus and Intermediate Hyperglycemia. Geneva, Switzerland: WHO; 2006.

27. WHO. Body Mass Index Classification; 2014. Available from: http://apps.who.int/bmi/index.jsp?introPage=intro_3.html. Accessed December 21, 2014.

28. Whitworth JA. World Health Organization (WHO)/International Society of Hypertension (ISH) statement on management of hypertension. J Hypertens. 2003;21(11):1983-1992.

29. Ethiopian Diabetes Association. 2014. Available from: http://www. diabetesethiopia.org.et/. Accessed June 17, 2014.

30. International diabetes federation Africa. Diabetes in Ethiopia-2013; 2014. Available from: http://www.idf.org/membership/afr/ethiopia. Accessed June 17, 2014.

31. Diouf A, Cournil A, Ba-Fall K, et al. Diabetes and hypertension among patients receiving antiretroviral treatment since 1998 in Senegal: prevalence and associated factors. ISRN AIDS. 2012;2012:621565.

32. Kabati CIA, Maurice HB, Msell T, Urio M. Evaluation of the prevalence of insulin dependent diabetes mellitus in HIV/AIDS patients in Muhimbili National Hospital, Dar es Salaam, Tanzania. Tanzania J Nat Appl Sci. 2010;1:1.

33. Puttawong S, Prasithsirikul W, Vadcharavivad S. Prevalence of lipodystrophy in Thai-HIV infected patients. J Med Assoc Thai. 2004;87:605-611.

34. Tzur F, Chowers M, Mekori Y, Hershko A. Prevalence of diabetes mellitus among Ethiopian-born HIV patients in Israel. J Int AIDS Soc. 2012;15(Suppl 4):18158.

35. Salehian B, Bilas J, Bazargan M, Abbasian M. Prevalence and incidence of diabetes in HIV-infected minority patients on protease inhibitors. J Natl Med Assoc. 2005;97:1088-1092.

36. Danciulescu R, Musat M, Cristescu V, Poiana C. The prevalence of diabetes mellitus in patients infected with human immunodeficiency virus on treatment with Antiretroviral drugs. Endocr Abstr. 2011;26:736.

37. Nsakashalo-Senkwe M, Siziya S, Goma FM, Songolo P, Mukonka V, Babaniyi O. Combined prevalence of impaired glucose level or diabetes and its correlates in Lusaka urban district, Zambia: a population based survey. Int Arch Med. 2011;4:2.

38. Jain MK, Aragaki C, Fischbach L, et al. Hepatitis C is associated with type 2 diabetes mellitus in $\mathrm{HIV}$-infected persons without traditional risk factors. HIV Med. 2007;8:491-497.

39. Butt AA, McGinnis K, Rodriguez-Barradas MC, et al. HIV infection and the risk of diabetes mellitus. AIDS. 2009;23:1227-1234.

40. Kalyanasundaram AP, Jacob SM, Hemalatha R, Sivakumar MR. Prevalence of lipodystrophy and dyslipidemia among patients with HIV infection on generic ART in rural South India. J Int Assoc Physicians AIDS Care. 2012;11:329-334.

41. Shen Y, Wang Z, Liu L, Zhang R, Zheng Y, Lu H. Prevalence of hyperglycemia among adults with newly diagnosed HIV/AIDS in China. BMC Infect Dis. 2013;13:79. 


\section{Publish your work in this journal}

Diabetes, Metabolic Syndrome and Obesity: Targets and Therapy is opinion and commentaries are all considered for publication. The an international, peer-reviewed open-access journal committed to the rapid publication of the latest laboratory and clinical findings in the fields of diabetes, metabolic syndrome and obesity research. Original research, review, case reports, hypothesis formation, expert manuscript management system is completely online and includes a very quick and fair peer-review system, which is all easy to use. Visit http://www.dovepress.com/testimonials.php to read real quotes from published authors.

Submit your manuscript here: http://www.dovepress.com/diabetes-metabolic-syndrome-and-obesity-targets-and-therapy-journal 